\title{
Peran Perawat dalam Penerapan Sasaran Keselamatan Pasien di Rumah Sakit
}

Jihan Asyla

191101021

Jihanasyla20.@gmail.com

\begin{abstract}
Abstrak
Penerapan keselamatan pasien dapat diwujudkan dengan menetapkan standar, sasaran dan langkah menuju keselamatan pasien dengan tujuan akhir yaitu memberikan asuhan pasien yang lebih aman. Upaya keselamatan pasien merupakan bagian tak terpisahkan dari proses asuhan keperawatan. Keselamatan pasien (patient safety) adalah suatu sistem dimana rumah sakit membuat asuhan pasien lebih aman, mencegah terjadinya cidera yang disebabkan oleh kesalahan akibat melaksanakan suatu tindakan atau tidak mengambil tindakan yang seharusnya diambil.
\end{abstract}

\section{Kata kunci : Perawat, Sasaran Keselamatan, Rumah Sakit.}

\section{Latar Belakang}

Keselamatan pasien (patient safety) adalah suatu sistem dimana rumah sakit membuat asuhan pasien lebih aman, mencegah terjadinya cidera yang disebabkan oleh kesalahan akibat melaksanakan suatu tindakan atau tidak mengambil tindakan yang seharusnya diambil. Sistem tersebut meliputi pengenalan resiko, identifikasi dan pengelolaan hal yang berhubungan dengan resiko pasien, pelaporan dan analisis insiden, kemampuan belajar dari insiden, tindak lanjut dan implementasi solusi untuk meminimalkan resiko (Depkes2008).

Upaya keselamatan pasien merupakan bagian tak terpisahkan dari proses asuhan keperawatan. Area praktek keperawatan yang berbasis pada keselamatan pasien meliputi :

A. Standar Praktik (Asuhan keperawatan)

Setiap perawat mempunyai tanggung jawab melakukan :

1. Assesment (Pengkajian) : Status kesehatan pasien saat ini dan masa lalu serta potensi resiko (keselamatan pasien)

2. Diagnosa : menetapkan diagnosa/ masalah keperawatan

3. Planning : Rencana asuhan keperawatan 
4. Implementation : Pelaksanaan asuhan sesuairencana

5. Evaluation : evaluasi terhadap respon pasien danoutcome

B. Standars Of Care :Safety

Setiap perawat menerapkan prinsip Sasaran Keselamatan Pasien (International Patient Safety Goals)

Penerapan keselamatan pasien dapat diwujudkan dengan menetapkan standar, sasaran dan langkah menuju keselamatan pasien dengan tujuan akhir yaitu memberikan asuhan pasien yang lebih aman (KEMENKES RI, 2017).

\section{Tujuan}

Kajian ini bertujuan untuk mengetahui peran perawat dalam keselamatan pasien baik itu di Rumah Sakit atau Puskesmas. Dan perawat diharapkan dapat menerapkan secara benar perannya dalam sasaran keselamatan pasien dirumah sakit agar menurunkan angka KTD (kejadian tidak diharapkan), KNC (kejadian nyaris cedera), KTC (kejadian tidak cedera), KPC (kejadian potensial cedera) yang sering terjadi pada pasien selama dirawat di rumah sakit yang akan sangatmerugikan pasien maupun pihak rumah sakit.2Dan juga dapat menerapkan prinsip sasaran keselamatan pasien tersebut supaya tujuannya tercapai.

\section{Metode}

Metode yang digunakan adalah metode kualitatif dengan cara mengumpulkan sebanyak-banyaknya data untuk dianalisis. Yaitu dengan literature review dengan menganalisis yang berfokus pada penerapan kebijakan keselamatan pasien di rumah sakit. Adapun tinjaun literature review yang digunakan seperti text book, journal, dan bukureferensi.2

\section{Hasil}

Berdasarkan hasil pengkajian kualitatif tersebut dapat diketahui metode yang digunakan untuk mengetahui apa saja peran perawat yang akan dilakukan untuk keselamatan pasien, yaitu meliputi Metode Pengumpulan Data dimana dalam penelitian kualitatif beberapa metode pengumpulan data dalam penelitian kualitatif ini dapat meningkatkan kemampuan perawat dalam berfikir kritis. Sehingga dengan adanya pengumpulan data ini akan membuat mahasiswa lebih banyak membacabaikitubukumaupunjurnal 
dan ini akan lebih mudah meningkatkan kemampuan berpikir kritis tersebut.

Indikator mutu rumah sakit meliputi indikator klinik, indikator yang berorientasi pada waktu dan indikator ratio yang berdasarkan pada efektifitas (effectivenes), efisiensi (efficiency), keselamatan (safety) dan kelayakan (appropriateness).

\section{Pembahasan}

Menurut Depkes (2008), Patient Safety (Keselamatan Pasien) merupakan suatu sistem dimana rumah sakit atau pelayanan kesehatan membuat asuhan pasien menjadi lebih aman, mencegah terjadinya cidera yang disebabkan oleh kesalahan akibat melaksanakan suatu tindakan atau tidak mengambil tindakan yang seharusnya diambil.

Tujuan dilakukannya kegiatan Patient Safety di rumah sakit adalah untuk menciptakan budaya keselamatan pasien di rumah sakit, meningkatkan akuntabilitas rumah sakit terhadap pasien dan masyarakat, menurunkan KTD (Kejadian Tidak Diharapkan) di rumah sakit, terlaksananya programprogram pencegahan sehingga tidak terjadi pengulangan kejadian tidak diharapkan (Kuntoro, 2010).
Dari definisi inilah, kita dapat mengetahui peran perawat dalam mewujudkan patient safety di rumah sakit yaitu:

1. Sebagai pemberi pelayanan keperawatan, perawat mematuhi standar pelayanan dan SOP yang telah ditetapkan

2. Menerapkan komunikasi yang baik terhadap pasien dankeluarganya

3. Peka, proaktif dan melakukan penyelesaian masalah terhadap kejadian tidak diharapkan(KTD)

4. Serta mendokumentasikan dengan benar semua asuhan keperawatan yang diberikan kepada pasien dankeluarga

5. Menerapkan prinsip-prinsip etik dalam pemberian pelayanan keperawatan

6. Memberikan pendidikan kepada pasien dan keluarga tentang asuhan yangdiberikan

7. Menerapkan kerjasama tim kesehatan yang handal dalam pemberian pelayanan kesehatan

Selain itu, perawat juga berperan untuk memberikan informasi kepada pasien dan keluarga tentang 
kemungkinan terjadinya resiko, meminimalkan resiko (Depkes 2008). melaporkan terjadinya KTD, Upaya keselamatan pasien merupakan meningkatkan komunikasi dengan bagian tak terpisahkan dari proses pasien dan tenaga kesehatan asuhan keperawatan.

professional lainnya, berperan aktif dalam melakukan pengkajian terhadap keamanan dan kualitas pelayanan dan membantu pengukuran terhadap peningkatan patient safety (Choo, 2010).

Sebagai contoh yaitu peran perawat dalam penggunaan peralatan dan teknologi dalam meningkatkan patient safety.

\section{Penutup}

Kesimpulan

Keselamatan pasien (patient safety) adalah suatu sistem dimana rumah sakit membuat asuhan pasien lebih aman, mencegah terjadinya cidera yang disebabkan oleh kesalahan akibat melaksanakan suatu tindakan atau tidak mengambil tindakan yang seharusnya diambil. Sistem tersebut meliputi pengenalan resiko, identifikasi dan pengelolaan hal yang berhubungan dengan resiko pasien, pelaporan dan analisis insiden, kemampuan belajar dari insiden, tindak lanjut dan implementasi solusi untuk

\section{Saran}

Hasil pengkajian ini menyarankan tentang pentingnya peran perawat dalam keselamatan pasien di Rumah Sakit. Dimana tahapan atau langkah ini harus dilaksanakan secara berurutan sehingga akan lebih mudah untuk dilaksanakan atau diterapkan oleh perawat maupun pelayan kesehatan lainnya. Peran perawat dalam pelaksanaan Sasaran Keselamatan Pasien perlu dioptimalkan dalam rangka peningkatan mutu dan keselamatan pasien.

\section{Referensi}

Arruum, D., salbiah, \& manik, m. (2015). PENGETAHUAN TENAGA KESEHATAN DALAM SASARAN KESELAMATAN PASIEN DI RUMAH SAKIT SUMATERA UTARA.Idea

Nursing Journal , VI (2), 1-6.

Ayuningtyas, Dumilah. (2014). Kebijakan Kesehatan Prinsip dan Praktik. Jakarta : Rajawali Pers. 
Basabih, M. (2017). Perlukah Keselamatan Pasien Menjadi Indikator Kinerja RS BLU? Jurnal ARSI , 3 (2), 150-157.

Cohen.2007. Protecting patients from harm: Reduce the risks of high alert drugs.

Clancy, C. (2011). New research highlights the role of patient safety culture \& safer care. Journal of nursing care quality/Juli-September.

Dr. Cipto Mangunkusumo.Sammer, C., Lykens, K., Singh, K., Mains, D., \& Lackan, N., (2010). What is Patient Safety Culture? A Review of the Literature. Journal of Nursing Scholarship, 42:2, 156-165.

insani, T. H., \& sundari, s. (2018). Analisis Pelaksanaan Keselamatan Pasien oleh Perawat. Journal of Health Studies , 2 (1), 84-95.

Keputusan Menteri Kesehatan Nomor 428 Tahun 2012 tentang Penetapan Lembaga Independen Pelaksanaan Akreditasi Rumah Sakit di Indonesia.

Komisi Akreditasi Rumah Sakit. 2017. Standar Nasional Akreditasi Rumah Sakit Edisi 1.
Komisi Akreditasi Rumah Sakit. (2012). Instrumen akreditasi rumah sakit standar akreditasi rumah sakit versi 2012. Jakarta : Komisi Akreditasi RumahSakit.

lombogia, a., rottie, j., \& karundeng, m. (2016). HUBUNGAN PERILAKU DENGAN KEMAMPUAN PERAWAT DALAM MELAKSANAKAN KESELAMATAN PASIEN (PATIENT SAFETY) DI RUANG AKUT INSTALASI GAWAT DARURAT. keperawatan, vol 2 (4), 1-8.

muhammad yusuf. (2017). Penerapan Patient Safety Di Ruang Rawat Inap Rumah Sakit Umum Daerah Dr. Zainoel Abidin. jurnal ilmu keperawatan , 5 (1),84-89.

Simamora, R. H. (2019). Buku Ajar: Pelaksanaan Identifikasi Pasien. ponorogo, Jawa Timur: Uwais Inspirasi Indonesis.

Simamora, R. H. (2019). Documentation of Patient Idntification into the Electronic System to Improve the Quality of Nursing Services. International 
Journal Of Scientific \& Technology

Research , 08 (09), 1884-1886.

Simamora, R. H. (2019, november 08).

Pengaruh Penyuluhan Identifikasi

Pasien dengan Menggunakan

Media Audiovisual terhadap

Pengetahuan Pasien Rawat Inap.

Jurnal Keperawatan Silampari, 342-251.

Undang-Undang Republik Indonesia

Nomor 44 tahun 2009 tentang

Rumah Sakit.
Undang-Undang Republik Indonesia Nomor 36 tahun 2014 tentang Tenaga Kesehatan.

World Health Organisation (WHO), 2010. Framework for Action on Interprofessional Education and Collaborative Practice. World Health Organisation, Geneva.

Yulia, S., Yani, A. (2012). Peningkatan Pemahaman Perawat Pelaksana Dalam Penerapan Keselamatan Pasien Melalui Pelatihan Keselamatn Pasien. Jurnal keperawatan indonesia. Vol. 15(3). Hal 190.6 